\title{
Evaluating effectiveness of screening house eaves as an intervention for integrated vector management for malaria control in Nyabondo, Western Kenya.
}

Peter Njoroge Ng'ang'a ( $\nabla$ pnganga2003@gmail.com )

International Centre for Insect Physiology and Ecology

Collins Okoyo

Kenya Medical Research Institute

Charles Mbogo

Kenya Medical Research Institute

Clifford Maina Mutero

ICIPE

Research

Keywords: Anopheles gambiae, House eaves screening, Malaria, Mosquitoes, Vector control

Posted Date: December 10th, 2019

DOI: https://doi.org/10.21203/rs.2.18504/v1

License: (c) (i) This work is licensed under a Creative Commons Attribution 4.0 International License.

Read Full License

Version of Record: A version of this preprint was published on September 19th, 2020. See the published version at https://doi.org/10.1186/s12936-020-03413-3. 


\section{Abstract}

\section{Background}

Mosquito-proofing of houses with appropriate screens fixed at potential mosquito entry points is gaining greater recognition as a practical intervention for reducing malaria transmission indoors. The study aimed at evaluating the effectiveness of house eaves screening in preventing mosquito entry and malaria prevalence in Nyabondo, western Kenya.

\section{Methods}

160 houses were selected for the study, with half of them randomly chosen for screening at the eaves with fibre-glass coated wire mesh (experimental group) and the other half left without screening (control group). Randomization was carried out by use of computer-generated list, in permuted blocks of ten houses and 16 village blocks in the study site, with treatments in the ratio of 1:1. Cross-sectional baseline entomological and malaria parasitological data were collected before house eave screening. After the baseline period, series of sampling of indoor adult mosquitoes were conducted once a month in each village using CDC light traps. Three cross-sectional malaria parasitological surveys were also conducted at three month intervals after installation of the screens. The primary outcome measures were indoor Anopheles mosquito density and malaria parasite prevalence.

\section{Results}

A total of 15,286 mosquitoes were collected over the two years period using CDC light trap in 160 houses distributed over 16 study villages (mean $=4.35, S D=11.48$ ). Of all mosquitoes collected, 2,872 were anophelines (2,869 An. gambiaes.l., 1 An. funestus and 2 other anopheles). Overall, among An. gambiae collected, $92.6 \%$ were non-blood fed, $3.57 \%$ were blood fed and the remaining $0.47 \%$ were composed of gravid and half gravid females. Overall more mosquitoes were collected in the control than experimental arms of the study. Results from four cross-sectional prevalence surveys showed that screened houses recorded relatively low malaria prevalence rates compared to the control houses. Overall, malaria prevalence was $5.6 \%(95 \% \mathrm{Cl}: 4.2-7.5) \mathrm{N}=1,918$, with baseline survey recording $6.1 \%$ prevalence $(95 \% \mathrm{Cl}$ : 3.9-9.4), $n=481$ and third follow-up survey recording $3.6 \%$ prevalence $(95 \% \mathrm{Cl}: 2.0-6.8) n=494$. At all the three follow-up survey points, house screening significantly reduced the malaria prevalence by $100 \%$ $(p<0.001), 63.6 \%(p=0.026)$, and 100\% ( $p<0.001)$ for first, second and third follow-ups surveys respectively. The house screening significantly reduced malaria prevalence by $54 \%(\mathrm{OR}=0.46,95 \% \mathrm{Cl}$ : $0.24-0.87, p=0.017)$.

\section{Conclusions}

The study demonstrated that house eave screening has potential to reduce indoor vector densities and malaria transmission in high transmission areas in Kenya. 


\section{Introduction}

Malaria remains a major public health problem in Kenya, accounting for approximately $21 \%$ of outpatient consultations and $3-5 \%$ of hospital admissions each year [1]. Malaria prevalence in the country and subSaharan Africa varies by season and across geographic regions [2,3]. Transmission and infection risk is determined largely by altitude, rainfall patterns, and temperature [4]. Approximately 70 percent of the Kenyan population is at risk of contracting malaria [1]. The government of Kenya remains committed to improving health service delivery and places a high priority on malaria prevention and control, with eventual malaria elimination listed as one of the strategic objectives of the Kenya Health Policy.

Vector control remains one of the most effective measure to prevent malaria transmission and is one of the core strategies for global malaria control [5]. The other strategies include accurate diagnosis and prompt treatment of clinical disease with appropriate drugs, particularly artemisinin-based chemotherapies $[5,6]$. Vector control efforts mainly aim at eliminating man-vector contact [6] The most widely embraced options for this purpose are the large-scale use of long-lasting insecticide-treated nets (LLINs), and the application of indoor residual spraying (IRS) [6, 7]. The two insecticide-based methods although regarded as being among the key factors that contributed to $50 \%-60 \%$ reduction of malaria globally from 2000 to 2015 are faced with serious challenges related to insecticide resistance in vector populations and availability of the necessary funding to support malaria control programmes $[8,9,10$, 11]. The World Health Organization's response to these perennial challenges includes the promotion of integrated vector management (IVM), involving the combining of existing primary interventions of LLINs and IRS with complementary methods such as house improvements and other environmental management measures $[12,13,14,15]$.

Although housing improvements historically contributed significantly to malaria elimination in Europe and the USA [16], only a few studies have been carried out to assess the potential of this approach in reducing malaria in settings of high transmission in the tropical and sub-tropical developing countries $[17,18,19,2021]$. Nevertheless, a recent systematic review and meta-analysis showed that housing is an important risk factor for malaria [22, 23]. The review concluded that further studies on housing improvements are warranted since clinical outcomes of the intervention have not been widely documented. In Africa and other parts of the tropics, traditional houses are often constructed with open eaves, which serve to increase airflow in the houses, but unfortunately also allow the entry of voracious malaria-carrying Anopheles mosquitoes [24, 25, 26, 27, 28]. Complete screening of the eaves could, therefore, potentially protect all persons sleeping inside the house, regardless of whether they regularly use a protective bednet.

The previously mentioned systematic review highlighted the absence of data from many geographical regions, lack of enough intervention studies and the high risk of bias within and across studies [22]. Progress towards building the required body of evidence includes a randomized controlled trial (RCT), conducted in Gambia, which evaluated a house screening intervention against malaria, epidemiological outcomes, social acceptability and durability $[21,29]$. A recent survey on community perceptions and 
knowledge regarding the protective nature of house screening in an area of high malaria transmission in western Kenya showed that more than $85 \%$ of household owners considered screening useful, although the majority of houses in the area were not screened [30]. Reasons for not using the method included perceptions that it was costly, and also lack of awareness regarding its effectiveness in protecting against malaria.

The aim of this study was to evaluate whether adding house-eaves screening to the conventional usage of LLINs in Nyabondo, western Kenya could lead to a significant reduction in the number of adult Anopheles mosquitoes found indoors and malaria prevalence in the community.

\section{Methodology}

\section{Study area}

The study was carried out in Nyabondo, a plateau area located in Upper Nyakach Division of Kisumu County, about $30 \mathrm{~km}$ North-East of Lake Victoria. Nyabondo lies between an altitude of 1,520m and $1,658 \mathrm{~m}$ above sea level, and $0^{\circ} 23^{\prime} 0 \mathrm{~S}$ and $34^{\circ} 58^{\prime} 60 \mathrm{E}$. The area is host to an estimated 34,000 people with a high population density of nearly 368 persons per square kilometer $(\mathrm{km})$. The main livelihood activities in the area include subsistence farming, mainly of maize, cassava and sweet potatoes, small scale livestock rearing, as well as brick-making $[31,15]$. Malaria is endemic in the Lake Victoria region, with a reported average prevalence of about $27 \%$ in $2015[1,4]$. Previous entomological surveys in Nyabondo found that larval Anopheles mosquitoes bred in both temporary and permanent habitats with An. arabiensis being the main malaria vector species (99.3\%), followed by An. gambiae (0.7\%) [32 33].

The overall poverty incidence in Nyabondo is approximately $61 \%$, perpetuated by inadequate agricultural technology, poor roads, water and sanitation systems [31]. Poor infrastructure, extreme weather conditions and poor resource management are among other constraints in this area. The majority of houses in Nyabondo were of local design, constructed with mud walls and iron sheets and a plaster finishing made by mixing ash, mud and cow dung [30].

\section{Study design}

The study enrolled a total of 16 villages, with a ratio of 1:1 villages among the control and treatment sites. In each village, there were 10 houses enrolled with 80 houses in each of the two study arms (control and intervention) for both entomological and epidemiological assessment. 80 out of the 160 houses were randomly selected for later screening of the eaves while the other 80 were designated as the control houses. Randomization was carried out by use of computer-generated list, in permuted blocks of ten houses and 16 village blocks in the study site, with treatments in the ratio of 1:1 (control vs treatment). For entomological assessment, all indoor resting mosquitoes were collected monthly for two years using CDC light traps between 19:00hours and 07:00hours. For epidemiological assessment, all persons living in the house at the time of the survey were tested for the presence of malaria parasite using RDT [34]. Malaria prevalence survey was done for four consecutive survey times (every three months) during the two years and included one baseline survey. 


\section{Entomological surveys}

Sampling of adult mosquitoes was conducted from September 2017 to November 2018. The sampling was spread out over a period of 16 days each month, with all the ten houses in a particular village being sampled in one night. Baseline data was collected during the first such sampling occasion while the postintervention sampling was conducted during the subsequent months. Sampling was conducted using CDC light traps with one light trap set up in an occupied bedroom per house and left to run for 12 hours overnight between 19:00hours and 07:00hours. Mosquitoes collected in the morning were killed using chloroform and morphologically identified in the field station as either belonging to anopheline or culicine group. Subsamples of anophelines were further identified morphologically to species level using keys of Gullies and De Mellon [35] with Gullies and Coetzee et al. [36] into sexed separated by physiological state, unfed and blood fed. Collections were done simultaneously for two years in both intervention and control houses and scheduled to span in both dry and wet seasons. The numbers of Anopheles gambiae vectors collected per trap night were used as a primary endpoint in assessing the efficacy of eave screening in reducing indoor vector densities.

\section{Malaria prevalence surveys}

Household malaria prevalence surveys were conducted after every three months from November 2017 to November 2018. The observed malaria prevalence was used as the epidemiological endpoint and diagnosis of Plasmodium falciparum was done by Rapid Diagnostic Tests (RDTs), using SD-Bioline malaria antigen P.f $\circledast$ test as recommended by the National Malaria Control Programme (NMCP) in Kenya [34]. The tests were performed following RDTs instructions guides [34, 37]. Individual socio-demographic information of the household members were collected in addition to the house characteristics. Consent to participate in this study was requested from the participant during the study. Individuals were asked whether they had taken any anti-malaria medication prior to the survey day. Participants found to be positive for malaria parasites were treated by the Ministry of Health staff according to the National Guidelines for malaria management in Kenya. RDTs were performed by a trained staff of the Ministry of Health following the manufacturer instructions [34,37]. Individual socio-demographic information of the household members was collected in addition to the house characteristics. Individuals were asked whether they had taken any anti-malaria medication prior to the survey day. Participants found to be positive for malaria parasites were treated according to the WHO Guidelines for malaria treatment and management [34].

\section{Eave screening procedure}

After randomization, and getting consent from household owners, screening houses were selected and fitted with a white polyester netting material designed to tightly and firmly fit onto pre-measured eave openings. An elastic cloth lining was sewn onto the edges of netting material by a tailor hired from the community and fixed onto position in the house eave using one inch nails as a harness. The screening work and roll-out roster was undertaken by project staff and local project youths, trained by an experienced consultant who was familiar with screening houses. Household occupants were encouraged 
during the entire study period to close windows and doors early in order to reduce mosquito entry into houses. Both Informed, verbal and written consent were sought from the head of each household before screens were installed into houses.

\section{Data management and statistical analysis}

Data was entered in MS Excel, cleaned and checked for errors by an independent person. Adult mosquito relative density was defined as the number of female adult anopheles mosquitoes per house per night. The 95\% confidence intervals (Cls) for the mean adult mosquito relative density were estimated using negative binomial regression model adjusted for household clusters. Mean mosquito population densities and the relative abundance of different vector species were compared between 2017 and 2018 . The effect of house screening intervention on adult mosquito density was estimated using generalized estimating equations (GEE), allowing for within-subject correlation using robust variance estimator to calculate standard errors (SEs). From the GEE model, we reported the incidence rate ratios (IRRs), the control arm (unscreened houses) was used as the reference against the experimental (screened houses).

For malaria epidemiological survey, Plasmodium falciparum infection was defined as a positive rapid diagnostic test (RDT) result. Proportion of individuals infected with malaria was calculated and the $95 \%$ confidence intervals (Cls) estimated using binomial logistic regression model that accounted for household clusters. The impact of house screening on infection prevalence was calculated and odds ratios (ORs) estimated using multilevel mixed effects logistic regression model while accounting for household clusters. All statistical analyses were performed using STATA version 14.1 (STATA Corporation, College Station, TX, USA) [38].

\section{Results}

\section{Indoor adult Mosquito collections}

Overall, 15,286 mosquitoes were collected over the two years using CDC light trap in 160 houses distributed over 16 study villages (mean $=4.35, S D=11.48$ ). Of all mosquitoes collected, 2,872 were anophelines (2,869 An. gambiae s.l., 1 An. funestus and 2 other anopheles), and 12,414 were culicines. Of the total 12,414 culicines collected in the two years, $20.59 \%$ were collected from screened houses compared to $79.41 \%$ collected from unscreened (control) houses respectively. Eaves screening reduced culicines densities during the same period. There was overall reduction in anopheles mosquito collected indoor in experimental houses compared to control houses during the sampling period despite nonsignificant difference in the mean number of mosquitoes [Table 1].

A total of 14,952 mosquitoes were unfed (2,749 An. gambiae, 0 An. funestus, and 12,203 culicines), 311 mosquitoes were fed (106 An. gambiae, 0 An. funestus, and 205 culicines), 6 were half gravid (6 An. gambiae, 0 An. funestus, and 0 culicines), and 15 were gravid (8 An. gambiae, 1 An. funestus, and 6 culicines). Overall, among An. gambiae collected, 92.6\% were non-blood fed [39], 3.57\% were blood fed and the remaining $0.47 \%$ were composed of gravid and half gravid females. However, irrespective of the 
species, more unfed, fed, half gravid and gravid mosquitoes were collected in the control than experimental arms of the study [Table 2].

\section{Impact of house screening on indoor mosquito densities}

On the overall impact of the house screening on adult mosquito density, the house screening nonsignificantly reduced the anopheline (majority being An. gambiae) mosquito density by $2 \%$ (IRR $=0.98$, $95 \% \mathrm{Cl}: 0.72-1.33, p=0.893)$. However, the screening did not show any impact on culicines density [Table 3].

\section{Impact of house screening on malaria incidence and prevalence}

Overall, malaria prevalence was $5.6 \%(95 \% \mathrm{Cl}: 4.2-7.5) n=1,918$, with baseline survey prevalence of $6.1 \%$ (95\% Cl: 3.9-9.4), $n=481$ and $3^{\text {rd }}$ follow-up survey prevalence of $3.6 \%(95 \% \mathrm{Cl}: 2.0-6.8) n=494$. This translated into a significant malaria prevalence reduction of $39.6 \%(p=0.045)$ from baseline to $3^{\text {rd }}$ follow-up survey. At all the three follow-up survey points, house screening significantly reduced the malaria prevalence by $100 \%(p<0.001), 63.6 \%(p=0.026)$, and $100 \%(p<0.001)$ in the $1^{\text {st }}, 2^{\text {nd }}$ and $3^{\text {rd }}$ follow-ups respectively [Table 4].

Figure 1 compares the malaria prevalence in both control and experimental groups at different survey points. Overall, the house screening significantly reduced malaria prevalence by $54 \%(\mathrm{OR}=0.46,95 \% \mathrm{Cl}$ : $0.24-0.87, p=0.017$ ), there were also significant impacts observed at each of the three follow-up survey points.

\section{Discussion}

Housing structure has been shown to be one of the factors influencing indoor vector densities and malaria transmission. Results from this study demonstrated that simple and affordable house design modification, such as eaves screening has the potential of reducing the overall mosquito densities in rural African settings. These observations challenged the previous report that demonstrated that house screening is too expensive and impractical for widespread use in most rural African houses that are made up of mud and sticks for the walls and grass thatch for the roofs [40]. Poorly constructed houses with eave gaps tend to have increased human-vector exposure, resulting in a higher risk of malaria transmission. Reduction in the number of mosquitoes indoors is expected to lead to a reduction in the number of infective bites which in turn would suppress malaria vector populations.

From our study, there was overall reduction in anopheles mosquito collected indoor in experimental houses compared to control houses during the sampling period. Similar observations have been made in the Gambia and Ethiopia where houses with ceiling, door and window screenings recorded a decrease in indoor resting mosquitoes $[20,21,41,42]$. It has been demonstrated that major malaria vectors are predominantly endophagic, nocturnal and mainly enter houses through the eaves and more than $80 \%$ of malaria transmission occurs indoors, primarily at night or in the later part of the night [43], therefore, 
installation of house screening is necessary. Night is therefore, the most vulnerable time for people to be bitten and infected with malaria or other mosquito-borne pathogens. The importance of eaves as the preferred entry point for Anopheles mosquitoes therefore, are suitable site to intercept as has been recognized by WHO since 1997. Thus, closing windows or screening of windows and open eaves has the potential to reduce the chances of mosquito bites, hence lowering the occurrence of malaria, where mosquitoes usually feed on people indoors [41, 42, 44]. In a related survey in Baringo, Kenya, houses with closed eaves had a low mean of mosquitoes compared to houses with open eaves while poor housing construction was associated with increased malaria incidence in a cohort of young Ugandan children [45, 46]. Atieli et al. 2009 demonstrated that house design modification by inclusion of a ceiling can reduce mosquito densities considerably. Furthermore, it has been observed that building houses with well fitted windows and doors would reduce mosquito entry as compared to traditional houses [47].

Although screening intervention reduced overall indoor density of An. gambiae in Nyabondo, the reduction was substantially higher against unfed $A n$. gambiae and culicines which formed the highest percentage of indoor adult mosquitoes collected during the two year period. A similar observation were made in a different but related study in Tanzania where out of the total number of female An. gambiae s.l., collected, approximately $98 \%$ were non-blood fed, $1.7 \%$ blood fed and the remaining $0.3 \%$ were gravid [39]. Out of the 12,389 female Culex adult mosquitoes collected during this period, $1.64 \%$ were blood fed. Though minimal, this percentage is of public health concern because several species serve as vectors of one or more important diseases of birds, humans, and other animals. The diseases they cause include arbovirus infections such as West Nile virus, Japanese encephalitis, or St. Louis encephalitis, and also Filariasis, Zika virus and avian malaria that are common in Africa [48].

Screened houses recorded relatively low malaria prevalence rates in the study area compared to the control houses for the whole period. However, during the third prevalence survey (second follow up) that was conducted in July-August 2018, both the intervention and control arms experienced an increase in prevalence rates during this period [Table 4 and Figure 1]. This could speculatively be partly attributed to less usage of personal protection measures during the hot seasons of the year when the rains subsided in the study area. Eaves screening has also been found to affect compliance to LLNs use in areas where household members perceive that they are protected by screening. During one of the follow up visits to screened houses in the study area, the project team found some LLNs being used to fence vegetable gardens in the compound. Reason given for this use was because the number of nuisance indoor mosquitoes had reduced in the area following eaves screening. Nevertheless, eave screening is most likely to be successful in areas where a large reduction in indoor biting is experienced by the occupants in order to substantially reduce malaria morbidity, especially in households where people prefer not to use bednets, or have stopped using them. The potential effect of house screening in reducing malaria prevalence and incidences has been demonstrated in several related studies in Africa. A randomized trial in the Gambia showed screening to be effective in reducing the level of anaemia in children [21]. In Dar es Salaam Tanzania, house screening contributed to a reduction in malaria transmission while in Uganda poor housing construction was associated with increased malaria incidence in a cohort of young Ugandan children $[46,49,50]$. Another potential advantage of house improvements and screening is the 
equity with which it protects all members of the household at all times while indoors, unlike LLINs which primarily give protection to those with a net during sleeping hours only. Perhaps the greatest benefit to house modifications would be its potential for integration with other vector control strategies and offering protection from other vector borne diseases as well as malaria. There is evidence that interventions which impede mosquito entry to houses could also protect inhabitants from filariasis, Rift Valley Fever and O’Nyong Nyong [48].

The role of meteorological factors as important drivers of malaria transmission was also evidenced. There was relatively high numbers of malaria vectors captured indoor that was related with high amount of average rainfall recorded especially for the months of April-May 2017. The same year had relatively high number of recorded malaria cases recorded in a nearby Nyabondo Mission Hospital compared to year 2018. Positive effect of rainfall on malaria transmission has been reported widely [51]. Temperature, rainfall and humidity have also been associated with increased dynamics of malaria vector population in Africa and therefore, with increased malaria epidemic risk in Ethiopia [52]. The onset of the rainy season has been associated with an increase in vector abundance, it provides breeding sites for mosquitoes to lay their eggs, and ensures a suitable relative humidity in East Africa of at least 50 to $60 \%$ to prolong mosquito survival [51]. Rainfall was significantly, associated with the occurrence of $P$. falciparum malaria parasites in western Kenya where Villages at similar altitudes, exhibited markedly different mosquito vector densities and risk of malaria infection $[53,54]$.

\section{Conclusion}

House screening is a promising, efficient and sustainable approach in reducing malaria transmission in rural areas of Sub Saharan Africa. It has the potential to be integrated with other control strategies, lessen the existing threat of insecticide resistance and the emergence of new vector-borne diseases and minimize environmental impact of vector control in East Africa.

\section{Declarations}

\section{Ethical approval and consent to participate}

The study ethical approval was granted by Kenya Medical Research Institute (KEMRI) through the /Scientific and Ethic Review Unit (SERU) protocol number 2675 as part of the Integrated Vector Management for Sustainable Malaria Control in East Africa study reference number KEMRI/RES/7/3/1.

Consent to participate in this study was written and verbally requested from the participant before and during the study. Objective of the study, confidentiality of the information, benefits and possible risks associated with the study were explained to the participants before commencement. After consenting, the head of the house was asked to sign two copies of the informed consent forms, of which, one remained with the head of the house and the other copy was kept by the study investigator.

\section{Consent for publication}


Not Applicable.

\section{Availability of data and materials}

The original data and materials used for this study are available from the corresponding author upon request.

\section{Competing interests}

The authors declare that they have no competing interests.

\section{Funding}

This research work was funded by Biovision (BV) Foundation, Project Number BV HH-07 / 2016-18. The study was done as part of the project 'Integrated vector management to improve health and livelihoods of communities in malaria-affected areas of Kenya'. Logistical and technical support for data collection was provided through ICIPE office-Kenya.

\section{Authors' contributions}

PNN participated in the study design, data collection, analyses, and drafting the manuscript in consultation with the other authors. CO participated in cleaning, cross checking, analysing and interpretation of statistical data. CM participated in conception of study design. CMM conceived the study, supervised it, reviewed, guided and participated in drafting the manuscript. All authors read and approved the final manuscript.

\section{Acknowledgements}

We would like to thank all the household owners for their hospitality, cooperation and consent to participate throughout the course of this study. We are also grateful to the house screening youth group, Mosquito Control in Nyabondo [MOCON] for their enthusiasm, perseverance and commitment during the house screening period. Many thanks also go to the other field staffs Polycarp Aduogo, George Oliech, Simon Cheruiyot, the Nurses and Laboratory technician from the Sub-County Ministry of Health who persevered the wet seasons during entire period of prevalence surveys. Final vote of thanks goes to both Directors of ICIPE and KEMRI, and Biovision for making this study possible.

\section{References}

1. Kenya Ministry of Health [KMOH]. Malaria Operational Plan FY 2018. US. President's Malaria Initiatives. Nairobi: 2018. https://www.pmi.gov/docs/default-source/ default-documentlibrary/malaria-operational-plans/fy18/fy-2018-kenyamalaria-operational-plan.pdf?sfvrsn5.

2. Cotter C, Sturrock, HJW, Hsiang MS, Liu J, Phillips AA, Hwang J, Gueye CS, Fullman N, Gosling RD, Feachem RGA. The changing epidemiology of malaria elimination: new strategies for new 
challenges. The Lancet. Elsevier. September 2013.

3. Kapesa, A., Kweka E.J., Harrysone Atieli H., Afrane Y.A., Kamugisha E., Lee M. C., Zhou, G. Githeko A.K., Guiyun Yan. (2018). The current malaria morbidity and mortality in different transmission settings in Western Kenya. PLoS ONE. 13(8): e0202031. https://doi.org/10.1371/journal.

4. NMCP-CDC: President's Malaria Initiative-National Malaria Control Program (NMCP). Kenya malaria operational plan FY 2019.

5. World Malaria Report. World Health Organization. Geneva. 2016

6. World Malaria Report. World Health Organization. Geneva. 2018

7. Bhatt S, Weiss DJ, Mappin B, Dalrymple U, Cameron E, Bisanzio D, et al. Coverage and system efficiencies of insecticide-treated nets in Africa from 2000 to 2017. 2015; 4:e09672.

8. Global plan for insecticide resistance management in malaria vectors. 2012, Available: http://www.who.int/malaria/ vector_control/ivm/gpirm/en/.

9. Bhatt S, Gething P. Insecticide-treated nets (ITNs) in Africa 2000-2016: coverage, system efficiency and future needs for achieving international targets. Malar J. 2014;13:029.

10. Barreaux P, Barreaux AMG, Sternberg ED, Suh E, Waite JL, Whitehead SA, et al. Priorities for broadening the malaria vector control tool kit. Trends Parasitol. 2017;33:763-74.

11. Ranson H, N'Guessan R, Lines J, Moiroux N, Nkuni Z, Corbel V. Pyrethroid resistance in African anopheline mosquitoes: what are the implications for malaria control? Trends Parasitol. 2011; 27:91-8.

12. WHO: Global strategic framework for integrated vector management. World Health Organization; 2004.

13. Handbook on Integrated Vector Management (IVM). Geneva: World Health Organization; 2012.

14. Beier JC, Keating J, Githure JI, Macdonald MB, Impoinvil DE, Novak RJ: Integrated vector management for malaria control. Malar J. 2008, 7(Suppl 1):S4.

15. Mutero C, Mbogo C, Mwangangi J, Imbahale S, Kibe L, Orindi B, Girma M, Njui,A, Lwande W, Affognon $\mathrm{H}$, Gichuki C, Mukabana W. An Assessment of Participatory Integrated Vector Management for Malaria Control in Kenya. Environmental Health Perspectives. 2015, Volume 123: 11.

16. Anderson L., D. Simpson, and M. Stephens." Durable Housing Improvements to Fight Malaria Transmission: Can we learn new strategies from past experience?" Healthy Housing Initiative- White Paper No.1. Habitat for Humanity International. Global Programs Department, Atlanta 2013.

17. Lindsay SW, Jawara M, Paine K, Pinder M, Walraven GE, Emerson PM. Changes in house design reduce exposure to malaria mosquitoes. Trop Med Int Health. 2003; 8:512-517.

18. Atieli H., D. Menya, A. Githeko, T. Scott. "House design modifications reduce indoor resting malaria vector densities in rice irrigation scheme area in western Kenya." Malar J. 2009; 8:108.

19. Liu J.X., T. Bousema, B. Zelman, S. Gesase, R. Hashim, C. Maxwell, D. Chandramohan, R. Gosling. "Is Housing Quality Associated with Malaria Incidence among Young Children and Mosquito Vector Numbers? Evidence from Korogwe, Tanzania." PLoS ONE 2014; 9(2). 
20. Kirby M.J., C. Green, P.M. Milligan, C. Sismanidis, M. Jasseh, D. Conway, S.W. Lindsay. Risk factors for house-entry by malaria vectors in a rural town and satellite villages in The Gambia." Malar J. 2008a; 7:2.

21. Kirby M.J., D. Ameh, C. Bottomley, C. Green, M. Jawara, P.J. Milligan, P.C. Snell, D. Conway, S.W. Lindsay. "Effect of two different house screening interventions on exposure to malaria vectors and on anaemia in children in The Gambia: a randomised controlled trial.” The 2009; 374:998-1009.

22. Tusting LS, Ippolito M, Kleinschmidt I, Willey B, Gosling R, Dorsey G, et al. The evidence for improving housing to reduce malaria: a systematic review and meta-analysis. Malar J. 2015;14:209.

23. Tusting LS, Bottomley C, Gibson H, et al (2017). Housing improvements and malaria risk in subSaharan Africa: A multi- country analysis of survey data. PLoS Medicine. 2017;14:e1002234.

24. Lindsay SW, Snow RW: The trouble with eaves; house entry by vectors of malaria. Trans R Soc Trop Med Hyg 1988, 82:645-646.

25. Schofield CJ, White GB: Engineering against insect borne diseases in the domestic environment. Housing design and domestic vectors of disease. Trans R Soc Trop Med Hyg 1984, 78:285-292.

26. Njie M, Dilger E, Lindsay SW, Kirby MJ. Importance of eaves to house entry by anopheline, but not culicine, mosquitoes. J Med Entomol. 2009; 46: 505-510.

27. Snow WF. Studies of house-entering habits of mosquitoes in The Gambia, West Africa: experiments with prefabricated huts with varied wall apertures. Med Vet Entomol. 1987, 1: 9-

28. Carter, A. D."Are housing improvements an effective supplemental vector control strategy to reduce malaria transmission? A Systematic Review." Thesis, Georgia State University. 2014.

29. Kirby M.J., P. Bah, C.O.H. Jones, A.H. Kelly, M. Jasseh, S.W. Lindsay. “Social Acceptability and Durability of Two Different House Screening Interventions against Exposure to Malaria Vectors, Plasmodium falciparum Infection, and Anemia in Children in The Gambia, West Africa." J. Trop. Med. Hyg. 2010; 83(5):965-972.

30. Peter N, Ng'ang'a, James Mutunga, George Oliech and Clifford M. Mutero (2019). Community knowledge and perceptions on malaria prevention and house screening in Nyabondo, Western Kenya. BMC Public Health. 2019, 19:423. https://doi.org/10.1186/s12889-019-6723-3.

31. Imbahale SS, Abonyo OK, Aduogo OP, Githure JI, Mukabana WR. Conflict between the need for income and the necessity of controlling endemic malaria. J Ecosystem Ecography. 2013; 3:129.

32. Howard AF, Omlin FX. Abandoning small-scale fish farming in western Kenya leads to higher malaria vector abundance. Acta Trop. 2008; 105:67-73.

33. Imbahale SS, Paaijmans KP, Mukabana WR, Lammeren R, Githeko AK, Takken W. A longitudinal study on Anopheles mosquito larval abundance in distinct geographical and environmental settings in western Kenya. Malar J. 2011; 10:81.

34. How to use a rapid diagnostic test (RDT): A guide for training at a village and clinic level (Modified for training in the use of the Generic Pf-Pan Test for falciparum and non-falciparum malaria). WHO, 2010. V1.2 
35. Gillies MT, De Meillon B. The Anophelinae of Africa south of the Sahara (Ethiopian Zoogeographical Region). Publications of the South African Institute for Medical Research. 1968;54

36. Coetzee M, Craig M, Le-Seuur D. Distribution of Africa malaria mosquitoes belonging to the Anopheles gambiae complex. Parasitology Today. 2000;16:74-77.

37. Malaria rapid diagnostic test performance: Results of WHO product testing of malaria RDTs: round 8 (2016-2018), World Health Organization, 2018.

38. 2015. STATA version 14.1 Base Reference Manual. College Station, TX: Stata Press. STATA Corporation, College Station, TX, USA.

39. Lwetoijera D.W., S.S. Kiware, Z.D. Mageni, S. Dongus, C. Harris, G.J. Devine, S. Majambere. "A need for better housing to further reduce indoor malaria transmission in areas with high bed net coverage." Parasites and Vectors. 2013; 6:57.

40. Wanzirah H, Tusting LS, Arinaitwe E, Katureebe A, Maxwell K, Rek J, et al. Mind the gap. house structure and the risk of malaria in Uganda children. PLoS One. 2015;10:e0117396.

41. Lindsay SW, Jawara M, Paine K, Pinder M, Walraven GE, Emerson PM. Changes in house design reduce exposure to malaria mosquitoes. Trop Med Int Health. 2003; 8:512-517.

42. Massebo F, Lindtjørn B. The effect of screening doors and windows on indoor density of Anopheles arabiensis in South-West Ethiopia: a randomized trial. Malar J. 2013;12: 319.

43. Huho B., O. Briet, A. Seyoum, C. Sikaala, N. Bayoh, J. Gimnig, F. Okumu, D. Diallo, S. Abdulla, T. Smith and G. Killeen. "Consistently high estimates for the proportion of human exposure to malaria vector populations occurring indoors in rural Africa." Int J Epidemiol. 2013, 42(1): 235-247.

44. Bradley J., A.M. Rehman, C. Schwabe, D. Vargas, F. Monti, C. Ela, M. Riloha, I. Kleinschmidt. "Reduced Prevalence of Malaria Infection in Children Living in Houses with Window Screening or Closed Eaves on Biko Island, Equatorial Guinea." PLoS ONE. 2013; 8(11).

45. Ondiba IM, Oyieke FA, Ong'amo GO, Olumula MM, Nyamongo IK, Estambale BBA (2018) Malaria vector abundance is associated with house structures in Baringo County, Kenya. PLOS ONE 13(6): https://doi.org/ 1371/journal.pone.0198970.

46. Snyman K, Mwangwa F, Bigira V, Kapisi J, Clark TD, Osterbauer B, et al. Poor housing construction associated with increased malaria incidence in a cohort of young Ugandan children. Am J Trop Med Hyg. 2015; 92(6):1207士13. https://doi.org/10.4269/ajtmh.14-0828 PMID:

47. Hiscox A, Khammanithong P, Kaul S, Sananikhom P, Luthi R, Hill N, et al. Risk factors for mosquito house entry in the Lao PDR. PLoS One. 2013; 8(5):e62769. https://doi.org/10.1371/journal.pone 0062769 PMID:

48. Ogoma S.B., D.W. Lweitoijera, H. Ngonyani, B. Furer, T.L. Russell, W.R. Mukabana, G. Killeen, S.J. Moore. "Screening Mosquito House Entry Points as a Potential Method for Integrated Control of Endophagic Filariasis, Arbovirus and Malaria Vectors." PLoS Negl. Trop 2010; 4(8).

49. Liu J.X., T. Bousema, B. Zelman, S. Gesase, R. Hashim, C. Maxwell, D. Chandramohan, R. Gosling. "Is Housing Quality Associated with Malaria Incidence among Young Children and Mosquito Vector Numbers? Evidence from Korogwe, Tanzania." PLoS ONE 2014; 9(2). 
50. Geissbühler Y, Kannady K, Chaki PP, Emidi B, Govella NJ et al. Microbial larvicide application by a large-scale, community-based program reduces malaria infection prevalence in urban Dar es Salaam,Tanzania. PLOS ONE. 2009, 4: e5107. doi:10.1371/journal.pone.0005107. PubMed: 19333402.

51. Shanks GD, Hay SI, Stern DI, Biomndo K, Snow RW: Meteorologic influences on Plasmodium falciparum malaria in the Highland Tea Estates of Kericho, Western Kenya. Emerg Infect Dis 2002, 8:1404-8.

52. Abeku TA, van Oortmarssen GJ, Borsboom G, de Vlas SJ, Habbema JD: Spatial and temporal variations of malaria epidemic risk in Ethiopia: factors involved and implications. Acta Trop 2003, 87:331-40.

53. Zhou G, Minakawa N, Githeko AK, Yan G: Climate variability and malaria epidemics in the highlands of East Africa. Trends Parasito/ 2005, 21:54-6.

54. Imbahale, SS, Mukabana, WR, Orindi, B, Githeko, A. K. and Takken, W Variation in Malaria Transmission Dynamics in Three Different Sites in Western Kenya. Journal of Tropical Medicine,

\section{Tables}

Table 1: Number of indoor mosquitoes collected in Nyabondo from Sept 2017-September 2018

\begin{tabular}{|c|c|c|c|c|c|}
\hline Study arm & $\begin{array}{l}\text { An. gambiae } \\
\text { N (mean; SD) }\end{array}$ & $\begin{array}{l}\text { An. } \\
\text { funestus } \\
\mathrm{N} \text { (mean; } \\
\mathrm{SD} \text { ) }\end{array}$ & $\begin{array}{l}\text { Other } \\
\text { anopheles } \\
\text { N (mean; } \\
\text { SD) }\end{array}$ & $\begin{array}{l}\text { Culicines } \\
\text { N (mean; SD) }\end{array}$ & $\begin{array}{l}\text { Total } \\
\text { N (mean; SD) }\end{array}$ \\
\hline Control & $\begin{array}{l}2,325(0.82 ; \\
\mathrm{SD}=3.77)\end{array}$ & $\begin{array}{l}1(0 ; \\
\mathrm{SD}=0.02)\end{array}$ & $\begin{array}{l}2(0 ; \\
S D=0.03)\end{array}$ & $\begin{array}{l}9,858(3.47 ; \\
\mathrm{SD}=9.11)\end{array}$ & $\begin{array}{l}12,186(4.29 ; \\
\mathrm{SD}=10.84)\end{array}$ \\
\hline Experimental & $\begin{array}{l}544(0.80 \\
\mathrm{SD}=3.17)\end{array}$ & $0(0 ; \mathrm{SD}=0)$ & $0(0 ; \mathrm{SD}=0)$ & $\begin{array}{l}2,556(3.77 ; \\
S D=12.85)\end{array}$ & $\begin{array}{l}3,100(4.57 \\
\mathrm{SD}=13.83)\end{array}$ \\
\hline $\begin{array}{l}\text { Diff (t-test; } \\
\text { p-value) }\end{array}$ & $\begin{array}{l}\mathrm{t}=-0.108 \\
\mathrm{p}=0.914\end{array}$ & $\begin{array}{l}t=-0.489, \\
p=0.625\end{array}$ & $\begin{array}{l}t=-0.691, \\
p=0.489\end{array}$ & $\begin{array}{l}\mathrm{t}=0.698 \\
\mathrm{p}=0.486\end{array}$ & $\begin{array}{l}\mathrm{t}=0.567 \\
\mathrm{p}=0.571\end{array}$ \\
\hline Overall & $\begin{array}{l}2,869(0.82 ; \\
\mathrm{SD}=3.66)\end{array}$ & $\begin{array}{l}1(0 ; \\
\mathrm{SD}=0.02)\end{array}$ & $\begin{array}{l}2(0 ; \\
\mathrm{SD}=0.02)\end{array}$ & $\begin{array}{l}12,414(3.53 ; \\
\mathrm{SD}=9.94)\end{array}$ & $\begin{array}{l}15,286(4.35 \\
\mathrm{SD}=11.48)\end{array}$ \\
\hline
\end{tabular}

Diff: P-value for the statistical difference in the mean number of mosquito collections in the control and experimental groups was calculated using student t-test at 95\% confidence interval.

Table 2: Number of mosquitoes collected by feeding status from Sept 2017-September 2018 


\begin{tabular}{|c|c|c|c|c|}
\hline Mosquito species & $\begin{array}{l}\text { Unfed } \\
\text { N (mean; SD) }\end{array}$ & $\begin{array}{l}\text { Fed } \\
\text { N (mean; SD) }\end{array}$ & $\begin{array}{l}\text { Half gravid } \\
\text { N (mean; } \\
\text { SD) }\end{array}$ & $\begin{array}{l}\text { Gravid } \\
\text { N (mean; } \\
\text { SD) }\end{array}$ \\
\hline \multicolumn{5}{|l|}{ Control } \\
\hline An. gambiae & $\begin{array}{l}2,208(0.78 ; \\
\mathrm{SD}=3.13)\end{array}$ & $\begin{array}{l}103(0.04 ; \\
\mathrm{SD}=0.90)\end{array}$ & $\begin{array}{l}6(0 ; \\
S D=0.11)\end{array}$ & $\begin{array}{l}8(0 ; \\
\mathrm{SD}=0.09)\end{array}$ \\
\hline An. funestus & 0 & 0 & 0 & $\begin{array}{l}1(0 ; \\
\mathrm{SD}=0.02)\end{array}$ \\
\hline $\begin{array}{l}\text { Other anopheles } \\
\text { (unidentified) }\end{array}$ & 0 & 0 & 0 & 0 \\
\hline Culicines & $\begin{array}{l}9,658(3.40 ; \\
\mathrm{SD}=8.88)\end{array}$ & $\begin{array}{l}197(0.07 ; \\
\mathrm{SD}=1.01)\end{array}$ & 0 & $\begin{array}{l}3(0 ; \\
\mathrm{SD}=0.03)\end{array}$ \\
\hline \multicolumn{5}{|l|}{ Experimental } \\
\hline An. gambiae & $\begin{array}{l}541(0.80 ; \\
\mathrm{SD}=3.15)\end{array}$ & $3(0 ; \mathrm{SD}=0.09)$ & 0 & 0 \\
\hline An. funestus & 0 & 0 & 0 & 0 \\
\hline Other anopheles & 0 & 0 & 0 & 0 \\
\hline Culicines & $\begin{array}{l}2,545(3.75 ; \\
\mathrm{SD}=12.82)\end{array}$ & $\begin{array}{l}8(0.01 ; \\
\mathrm{SD}=0.15)\end{array}$ & 0 & $\begin{array}{l}3(0 ; \\
\mathrm{SD}=0.09)\end{array}$ \\
\hline \multicolumn{5}{|l|}{ Overall } \\
\hline An. gambiae & $\begin{array}{l}2,749(0.78 \\
\mathrm{SD}=3.14)\end{array}$ & $\begin{array}{l}106(0.03 ; \\
\mathrm{SD}=0.81)\end{array}$ & $\begin{array}{l}6(0 ; \\
S D=0.10)\end{array}$ & $\begin{array}{l}8(0 ; \\
S D=0.08)\end{array}$ \\
\hline An. funestus & 0 & 0 & 0 & $\begin{array}{l}1(0 ; \\
\mathrm{SD}=0.02)\end{array}$ \\
\hline Other anopheles & 0 & 0 & 0 & 0 \\
\hline Culicines & $\begin{array}{l}12,203(3.47 ; \\
\mathrm{SD}=9.76)\end{array}$ & $\begin{array}{l}205(0.06 ; \\
\mathrm{SD}=0.91)\end{array}$ & 0 & $\begin{array}{l}6(0 ; \\
\mathrm{SD}=0.05)\end{array}$ \\
\hline
\end{tabular}

Table 3: Impact of house screening on indoor adult mosquito density using generalized estimating equations 


\begin{tabular}{|c|l|l|l|}
\hline $\begin{array}{l}\text { Mosquito } \\
\text { density }\end{array}$ & $\begin{array}{l}\text { Overall } \\
\text { IRR, } \mathrm{p} \text {-value }\end{array}$ & $\begin{array}{l}\mathbf{2 0 1 7} \\
\text { IRR, } \mathrm{p} \text {-value }\end{array}$ & $\begin{array}{l}\mathbf{2 0 1 8} \\
\text { IRR, } \mathrm{p} \text {-value }\end{array}$ \\
\hline An. gambiae & & & \\
\hline Control & Reference & & \\
\hline Experimental & $\begin{array}{l}0.98(0.72-1.33), \\
\mathrm{p}=0.899\end{array}$ & $\begin{array}{l}0.90(0.58-1.41), \\
\mathrm{p}=0.654\end{array}$ & $\begin{array}{l}1.04(0.70-1.57), \\
\mathrm{p}=0.833\end{array}$ \\
\hline An. funestus & & & \\
\hline Control & Reference & & 0 \\
\hline Experimental & $0, \mathrm{p}=0.996$ & 0 & \\
\hline All anophelines & & & $1.04(0.70-1.57)$, \\
\hline Control & Reference & & $\mathrm{p}=0.833$ \\
\hline Experimental & $0.98(0.72-1.33)$, & $0.90(0.58-1.40)$, & \\
\hline pll mosquitoes & & $\mathrm{p}=0.645$ & \\
\hline Control & Reference & & $\begin{array}{l}1.07(0.86-1.35), \\
\mathrm{p}=0.536\end{array}$ \\
\hline Experimental & $1.07(0.92-1.24)$, & $\begin{array}{l}1.05(0.87-1.27), \\
\mathrm{p}=0.579\end{array}$ & \\
\hline
\end{tabular}

Table 4: Malaria prevalence and house screening impact on malaria infection in Nyabondo from Sept 2017-September 2018

Figures 


\begin{tabular}{|c|c|c|c|c|c|}
\hline Characteristic & Baseline & $\begin{array}{l}1^{\text {st }} \\
\text { follow-up }\end{array}$ & $\begin{array}{l}2^{\text {nd }} \text { follow- } \\
\text { up }\end{array}$ & $\begin{array}{l}3^{\text {rd }} \\
\text { follow-up }\end{array}$ & Overall \\
\hline \multicolumn{6}{|l|}{ Demographics } \\
\hline \# Villages (\# houses) & $16(160)$ & $15(150)$ & $16(160)$ & $16(160)$ & $16(160)$ \\
\hline $\begin{array}{l}\text { Household } \\
\text { membership: median } \\
\text { (range) }\end{array}$ & $4(1-8)$ & $4(1-8)$ & $4(1-8)$ & $4(1-8)$ & $4(1-8)$ \\
\hline Age: mean (range); $\mathrm{N}$ & $\begin{array}{l}20.9(0-90) ; \\
478\end{array}$ & $\begin{array}{l}21.0(0- \\
91) ; 481\end{array}$ & $\begin{array}{l}21.2(0-91) ; \\
457\end{array}$ & $\begin{array}{l}21.3(0- \\
91) ; 493\end{array}$ & $\begin{array}{l}\text { 21.1 (0- } \\
91) ; 1909\end{array}$ \\
\hline \multicolumn{6}{|c|}{ Gender: \# infected/\#sampled (\%) } \\
\hline Male & $9 / 208(4.3 \%)$ & $\begin{array}{l}11 / 208 \\
(5.3 \%)\end{array}$ & $\begin{array}{l}15 / 190 \\
(7.9 \%)\end{array}$ & $\begin{array}{l}7 / 206 \\
(3.4 \%)\end{array}$ & $\begin{array}{l}42 / 812 \\
(5.12 \%)\end{array}$ \\
\hline Female & $\begin{array}{l}20 / 273 \\
(7.3 \%)\end{array}$ & $\begin{array}{l}11 / 275 \\
(4.0 \%)\end{array}$ & $\begin{array}{l}23 / 272 \\
(8.5 \%)\end{array}$ & $\begin{array}{l}11 / 288 \\
(3.8 \%)\end{array}$ & $\begin{array}{l}65 / 1108 \\
(5.87 \%)\end{array}$ \\
\hline \multicolumn{6}{|c|}{ Infection prevalence, \% (95\%CI)* } \\
\hline Control & $5.2(3.4-8.1)$ & $\begin{array}{l}6.9(5.0- \\
9.4)\end{array}$ & $\begin{array}{l}10.1(6.6- \\
15.3)\end{array}$ & $\begin{array}{l}4.1(2.2- \\
7.9)\end{array}$ & $\begin{array}{l}6.3(4.8- \\
8.3)\end{array}$ \\
\hline Experimental & $10(4.5-22.2)$ & 0 & $\begin{array}{l}3.7(1.3- \\
10.7)\end{array}$ & 0 & $\begin{array}{l}3.0(1.5- \\
6.0)\end{array}$ \\
\hline $\begin{array}{l}\text { Risk reduction, \% } \\
\text { (p-value) }\end{array}$ & increase & $\begin{array}{l}100 \% \\
(p<0.001)\end{array}$ & $\begin{array}{l}63.6 \% \\
(p=0.026)\end{array}$ & $\begin{array}{l}100 \% \\
(p<0.001)\end{array}$ & $\begin{array}{l}52.4 \% \\
(p=0.019)\end{array}$ \\
\hline Total & $6.1(3.9-9.4)$ & $\begin{array}{l}4.6(3.5- \\
5.9)\end{array}$ & $\begin{array}{l}8.2(5.1- \\
13.2)\end{array}$ & $\begin{array}{l}3.6(2.0- \\
6.8)\end{array}$ & $\begin{array}{l}5.6(4.2- \\
7.5)\end{array}$ \\
\hline \multicolumn{6}{|c|}{ House screening impact on infection prevalence, OR $(95 \% \mathrm{CI}), \mathrm{p}$-value ${ }^{\circledR}$} \\
\hline Control & Reference & & & & \\
\hline Experimental & $\begin{array}{l}2.01(0.88- \\
4.57) \\
p=0.096\end{array}$ & $\begin{array}{l}0 \\
p<0.001\end{array}$ & $\begin{array}{l}0.35(0.14- \\
0.85) \\
p=0.021\end{array}$ & $\begin{array}{l}0 \\
\mathrm{p}<0.001\end{array}$ & $\begin{array}{l}0.46(0.24- \\
0.87) \\
p=0.017\end{array}$ \\
\hline \multicolumn{6}{|c|}{$\begin{array}{l}\text { *Malaria infection prevalence was calculated and 95\% confidence intervals estimated using binomial logistic } \\
\text { regression model while accounting for house clustering } \\
{ }_{\text {@ The impact of house screening on malaria infection prevalence was calculated and odds ratios (ORs) estimated }} \\
\text { using multilevel mixed effects logistic regression model while accounting for house clustering }\end{array}$} \\
\hline
\end{tabular}




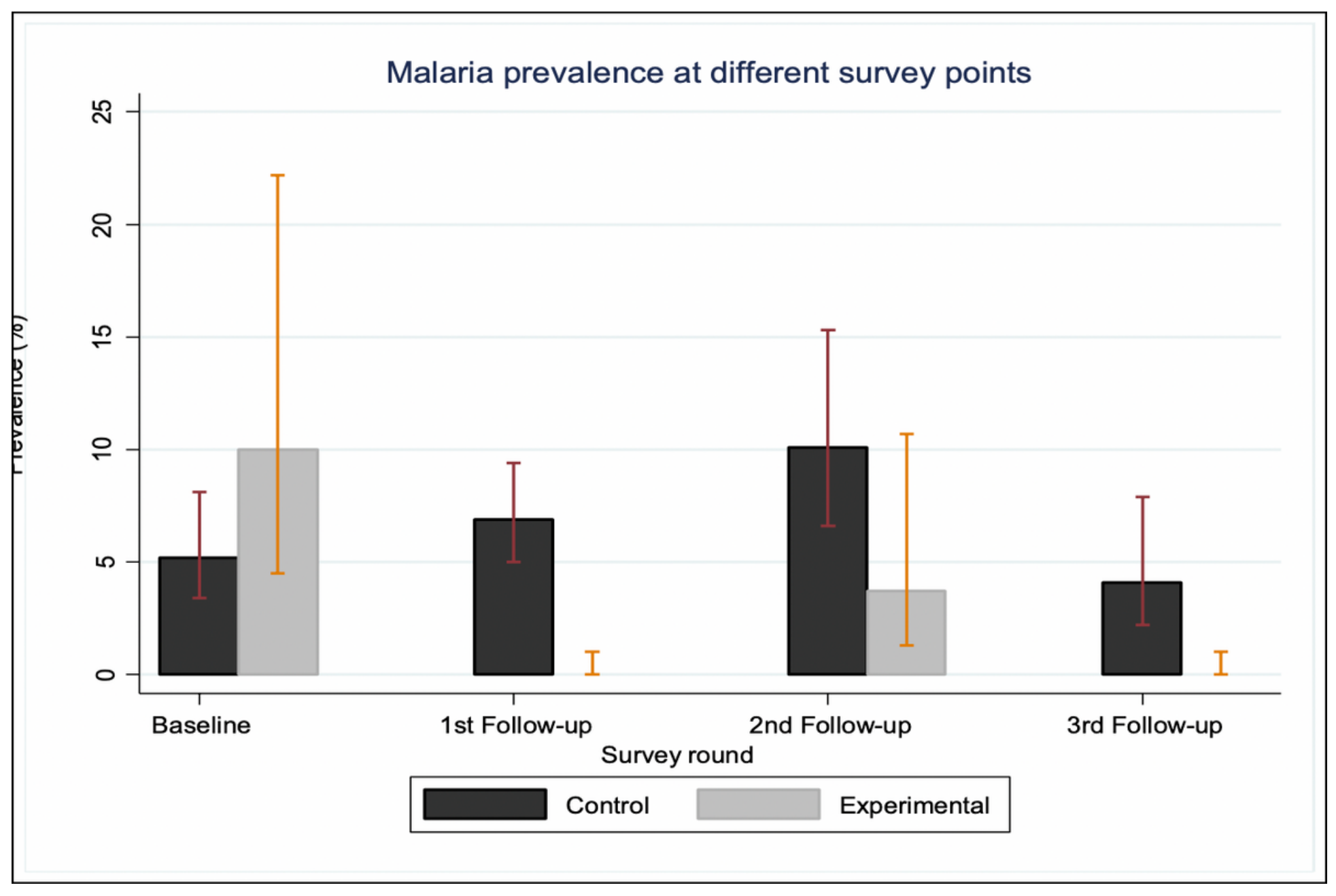

Figure 1

Comparison of malaria prevalence in both control and experimental groups at different survey points 